\title{
BENEFÍCIOS DOS PARQUES URBANOS
}

\section{Raphael Tavares Pacheco Martins}

Graduando de Arquitetura e Urbanismo/ISECENSA/Campos dos Goytacazes/RJ/Brasil

raphaelmartins.arq@gmail.com

\section{Ronaldo de Sousa Araújo}

Doutor em Gestão e Valoração Urbana/UPC/Barcelona/Espanha

r.saraujo@terra.com.br

\section{RESUMO}

Esta pesquisa teve como objetivo apresentar o tema e analisar os benefícios gerados pelos parques urbanos. Para a sua realização foi definido como zona de estudo a região norte do estado do Rio de Janeiro. Os outros objetivos foram a qualificação e a definição das funções do parque e a elucidação da sua contribuição para a melhoria da qualidade de vida. Além do lazer, outras funções socioambientais relevantes são desempenhadas pelos parques urbanos destacando-se a psicológica, a reconstrução da tranquilidade, a recomposição do temperamento, atenuante de ruídos e condicionador do microclima, impondo a sua inclusão no planejamento e nas políticas públicas das cidades. A pesquisa foi estruturada por um levantamento histórico e uma revisão bibliográfica. Um dos principais efeitos dos parques urbanos é a amenização climática, com contribuições positivas para o microclima local. No passar dos anos por conta dos grandes lucros as empresas privadas levaram o conjunto urbano para um crescimento desordenado e minimizando a função social dos parques urbanos, criando problemas sociais, esquecendo-se dos valores pessoais, históricos, culturais alem da dimensão sensorial e psicológica.

Palavras-chave: Parques urbanos; Áreas verdes; Cidades.

\section{ABSTRACT}

This research aimed to examine the positive effects generated by urban parks. For its completion was defined as the study area the state of Rio de Janeiro, with main focus on the northern region. The other objectives were the qualifying and defining the functions of the park and the elucidation of their contribution to improving the quality of life. Besides leisure, other relevant social and environmental functions are performed by urban parks highlighting the psychological, the reconstruction of peace, the rebuilding of temperament, mitigating noise and microclimate conditioner, requiring their inclusion in planning and public policy of the cities. The research was structured by a historical survey and a literature review. One of the main effects is climate mitigation, with positive contributions to local microclimate. Over the years owing to the big profits the private companies took the urban area to a disordered growth, minimizing the social function of urban parks, creating social problems, forgetting the personal, historical, cultural values beyond the sensory and psychological dimension.

Keywords: Urban parks; Green areas; Cities.

\section{INTRODUÇÃO}

Atualmente, a vida dos cidadãos tem sido um caos quando se fala em estresse, preocupação, trabalho e tudo mais. No entanto esses problemas cotidianos têm afetado muito nas relações sociais e intrafamiliares do brasileiro. Nas cidades, a habitação multifamiliar em massa e a verticalização têm aumentado muito nesses últimos anos e, condicionados a viabilidade orçamentária, o espaço de convivência desses locais vem decrescendo, a ponto de que cidadãos acabam necessitando de locais públicos urbanos para usufruir do ar livre.

A existência de parques urbanos nas metrópoles e a sua utilização, trazem inúmeros benefícios para a saúde do ser humano, como a apreciação da natureza, a reconstrução da tranquilidade, a recomposição do 
temperamento e também atenuante de ruídos e condicionador de microclima. Foram realizadas algumas entrevistas, e percebe-se que a amenização climática é um grande fator benéfico para os cidadãos brasileiros.

Olhando o cenário atual da nossa região Norte Fluminense, e comparando com os demais países até mesmo do nosso continente pode-se perceber a precariedade de áreas verdes urbanas, áreas de convivência, lazer e vazios urbanos.

Este artigo é uma revisão bibliográfica, que em primeiro lugar, foi fundamentada em pesquisas históricas bibliográficas, conceitos de espaços livres públicos, espaços verdes urbanos, áreas verdes, parques urbanos, paisagem, sutentabilidade ampliada e qualidade de vida.

Também foram discutidos alguns conceitos de espaço livre, arborização urbana, florestas urbanas, área livre e área aberta, espaço aberto, área verde e a sua subdivisão em praça jardim e os parques urbanos, todos inseridos nas diversas terminologias dos espaços livres urbanos; definições origens e tipos nos seus diferentes períodos na história da urbanização das cidades. A partir deste entendimento, foram abordadas as questões relacionadas com a apresentam-se a história e a evolução dos parques urbanos, desde os jardins italianos do século XVI até os atuais parques temáticos, litorâneos e ecológicos.

Deste modo, o objetivo deste estudo é expor para os cidadãos, novos empreededores e construtoras os benefícios de grandes parques urbanos nas pequenas e grandes cidades.

\section{A CIDADE INDUSTRIAL}

A habitação por conta da primeira Revolução Industrial necessitou de mão-de-obra interior ocasionando a vinda das pessoas para as cidades. E para minimizar a tensão da vida, os espaços livres surgiram do imaginário burguês, que buscava amenizar os problemas sociais, que se tornaram extremamente graves (SOUZA, 2003)

A cidade industrial moderna colocou a exigência de áreas verdes, parques e jardins, como elemento urbanístico, como ornamentação urbana, necessidade higiênica, recreação, defesa e recuperação do meio ambiente. A arborização das vias públicas, além de embelezá-las, é também um fator de atenuação de ruídos, de fixação e retenção do pó e da reoxigenação do ar (SILVA, 1947). Em termos de prazer cotidiano, também utilizado como refúgio e também criando significado social de uma área, sua função, sua história, ou mesmo seu nome (LYNCH, 1997).

\section{PARQUES URBANOS NO BRASIL}

No Brasil a presença de praças e largos vem de longa data, remontando aos primeiros séculos da colonização. Sobre esses espaços recaíam as atenções principais dos administradores, pois constituíam pontos de atenção e focalização urbanística, localizando-se ao redor da arquitetura de maior apuro, já que pontos de concentração da população (REIS FILHO, 1968).

"Ainda em relação aos índices é importante comentar que está difundida e
arraigada no Brasil á assertiva de que a ONU, ou a OMS, ou FAO, considerariam
ideal que cada cidade dispusesse de $12 \mathrm{~m}^{2}$ de área verde/habitante. Nas pesquisas,
por carta, que fizemos junto á essas Organizações, foi constatao que esse índice
não é conhecido, como não o é, entre as faculdades de paisagismo da República
Federal da Alemanha. Somos levados a supor, depois de termos realizado muito
estudos, que esse índice se refira, tão somente ás necessidades de parque de bairro
e distritais/setoriais, já que são os que, dentro da malha urbana, devem ser sempre
públicos e oferecem possibilidade de lazer ao ar livre" (CAVALHEIRO \& DEL
PICCHIA, 1992)

Paiva e Gonçalves (2002) exemplificam o conceito do que é o da floresta urbana, valorizando a árvore como um elemento do ambiente urbano. As florestas urbanas se referem aos conjuntos arbóreos criados pelo homem, inseridas nos núcleos urbanos. Seguindo o conceito de Cidade-Jardim segundo Ebenezer Howart, na verdade, não há somente duas alternativas como se crê - vida urbana ou vida rural. 
Existe também uma terceira perfeita harmonia entre ambas. A cidade e o campo poderiam ser vistos como dois ímãs, cada um buscando atrair as pessoas para si (HOWARD, 1996).

\section{BENEFÍCIOS DA ARBORIZAÇÃO}

Os espaços livres desempenham, no amplo sentido, integrar espaços diferentes, baseando-se no enfoque estético, como ecológico e lazer (CAVALEIRO; DEL PICCHIA, 1992, p.31). [...] As áreas verdes devem ser dotadas de infraestrutura e equipamentos oferecendo lazer e recreação e que possa ser percorrida de sua casa até lá a pé (MAZZEI, 2007).

Ferreira (2005) pesquisou sobre os benefícios que a vegetação pode trazer ao ser humano das cidades são encontrados em vários autores:

Estabilização de determinadas superfícies (...) as raízes ajudam a fixar o solo; obstáculo contra o vento (...); proteção da qualidade da água, pois impede que poluentes escorram para os rios (...); filtra o ar (...); equilibra o índice de umidade no ar (...); diminui a poeira; reduz o barulho; propicia a interação entre as atividades humanas e o meio ambiente; protege as nascentes e os mananciais; cria abrigo à fauna; é um componente da organização e composição de espaços no desenvolvimento das atividades humanas; é um elemento de valorização visual, ornamental; refresca a atmosfera; acompanhamento viário aumentando a segurança das calçadas; a psicologia indica que para a saúde psíquica do homem é necessário um suficiente contato com a natureza; função recreativa; árvores decíduas lembrariam ao homem as mudanças de estação; contraste de textura (...) delícias, mistérios e riquezas de detalhes (...); consumo de vegetais e frutas frescas; quebra da monotonia das cidades; cores relaxantes; renovação espiritual; o desconforto psicológico causado pelas grandes massas edificadas é amenizado pela presença de árvores, pois estas estabelecem uma escala intermediária entre a humana e a construída, atenuando imagens urbanas agressivas; caracterizam e sinalizam espaços; podem evocar a história dos mesmos; "purificação" das vias respiratórias (GEISER, et. al., 1975 e 1976; DI FIDIO, 1985; MARCUS \& DETWYLER, 1972; DOUGLAS, 1983; CAVALHEIRO, 1991; FELLENBERG, 1980).

São exemplos de benefícios que a vegetação pode trazer ao ser humano das cidades: Estabilização de determinadas superfícies (as raízem ajudam a fixas o solo), obstáculos contra o vento, proteção da qualidade da água (impede que poluentes escorram para os rios, filtro do ar diminui a poeira e equilibra a umidade), reduz o barulho, cria abrigo à fauna, valorização visual e ornamental, (...) (GEISER, 1975 e 1976).

Costa (1996) afirma que o conceito de arborização urbana não é limitado a presença de árvores nos parques públicos. Estão presentes em diversas tipologias dos espaços livres, como praças, ruas, largos, becos, florestas urbanas, entre outros e inclusive nos espaços que não receberam intervenção paisagística.

\section{FUNÇÕES URBANAS}

Quando se trata de funções urbanas, Llardent (1982) retrata a história desses espaços livres dizendo que: a cidade é um conjunto de elementos, sistemas e funções entrelaçados. Este é um marco concreto, onde deve contemplar a evolução dos espaços livres como um dos principais sistemas que formam o organismo urbano.

Para Vieira (2004), as áreas verdes assumem diferentes funções como: função social, função estética, função ecológica, função educativa e função psicológica. A esse respeito, analisar a estruturação dos espaços verdes na malha urbana, mostrando assim como ocorreu a apropriação do território brasileiro e a importância desse espaço na formação da cidade (SEGAWA, 1996). Os espaços de convivência e comemorações, ou seja, praças torna-se importante, pois a vida pública se desenvolvia e se hierarquizava por meio delas (ANDRADE, 2004). Segundo Macedo (1999), os espaços livres das residências brasileiras se estruturavam de forma única, regular, em função do parcelamento do solo, com quintais nos fundos. Este padrão colonial permaneceu até final do século XIX. 
Segundo Vieira (2004), as áreas verdes assumem diferentes papéis na sociedade e suas funções estão relacionadas no ambiente urbano como:

Função Social: possibilidade de lazer que essas áreas oferecem à população. Com relação a este aspecto, deve-se considerar a necessidade de hierarquização; Função Estética: diversificação da paisagem construída e embelezamento da cidade. Relacionada a este aspecto deve ser ressaltada a importância da vegetação; Função ecológica: provimento de melhorias no clima da cidade e na qualidade do ar, água e solo, resultando no bem estar dos habitantes, devido à presença da vegetação, do solo não impermeabilizado e de uma fauna mais diversificada nessas áreas; Função Educativa: possibilidade oferecida por tais espaços como ambiente para o desenvolvimento de atividades educativas, extraclasse e de programas de educação ambiental; Função Psicológica: possibilidade de realização de exercícios, de lazer e de recreação que funcionam como atividades "antiestresse" e relaxamento, uma vez que as pessoas entram em contato com os elementos naturais dessas áreas.

As atividades recreativas requerem espaços livres apropriados, esparsos por toda cidade, as zonas verdes para o jogo e para o esporte perto das casas, os parques dos bairros, os parques da cidade, as grandes zonas protegidas do território (BENEVOLO,1993).

Dentro dessa perspectiva, Rezende (2003) buscou iluminar as relações entre o planejamento urbano e o planejamento ambiental, que, mesmo estando presente em textos da Constituição Federal de 1988 e no Estatuto da Cidade, faz retornar as discussões sobre os importantes instrumentos de controle do solo urbano, entre eles o Plano Diretor, que avança quando dispõe sobre o meio ambiente urbano.

\section{PARQUES URBANOS E SEUS EFEITOS POSITIVOS}

Ao longo dos séculos, foram sendo acrescentados anéis urbanos, substituindo a vegetação pela pedra e destruindo as superfícies verdes, pulmões da cidade. Nessas condições, as altas densidades significam o mal-estar e a doença em estado permanente. (LE CORBUSIER, 1989)

A literatura atual, quebra a categoria "parques" em três novas categorias, parques urbanos, parque de área natural, e parques especiais ou específicos. A determinação do tamanho dos espaços abertos pode vir a maximizar o valor de venda de uma casa, e isso varia de acordo com os tipos de espaços abertos refletindo em uma contribuição adicional no valor. O estudo de Resenberger e Walsh (1997), inclue geralmente uma medida do tamanho do espaço aberto na equação de regressão, e não de forma quadrática. O estudo que tem como base Western Valley Ranchland-USA, representa a valorização do contingente.

As forças internacionais para preservar o meio ambiente, estão preocupadas principalmente com os diversos ecossistemas existentes. Tanto com os considerados relativamente grandes quanto com espécies animais ou vegetais individuais em perigo ou ameaçadas de extinção. Pouca atenção está sendo dada do meio político neste assunto, principalmente na natureza próxima de onde as pessoas vivem e trabalham, pequenos espaços verdes nas cidades, e menos ainda quando se tratam de benefícios para a população urbana. A sustentabilidade e as estratégias de regeneração das cidades deve se concentrar principalmente nas construções sendo empreendidas no ambiente urbano. A atenção para os elementos naturais e os espaços verdes da estrutura urbana ainda é pobre e a baixa valorização dos espaços verdes, também se reflete nos recentes cortes na manutenção do orçamento de muitas cidades. (TYRVAINEN \& VAANANEN, 1998).

Para Herculano (2000), o consumismo desenfreado do mundo contemporâneo poderia estar relacionado com a percepção queixosa sobre a baixa qualidade da própria vida. Escravos do consumo, estaríamos condenados a querer mais, a economizar mais e, portanto, a não usufruir dos prazeres da vida e buscar a felicidade de forma mais simples. A oportunidade de estar em contato com a natureza, em atividades de lazer ativo, passivo ou contemplativo faz a integração do homem com a natureza de forma harmônica.

A influência da vegetação na temperatura do ar está relacionada com o controle da radiação solar, do vento e da umidade do ar. A umidade do ar dos recintos urbanos está relacionada com a evapotranspiração. Esse efeito dependerá do albedo, morfologia e rugosidade. As maiores variações da umidade relativa do ar sob os grupamentos arbóreos ocorrem no verão (10\% UR), enquanto na primavera notam-se as menores 
diferenças (3\% UR). A incidência do vento sob os grupamentos é a responsável pela redução dessas diferenças de temperatura e umidade relativa entre as ares sombreadas e ensolaradas (MASCARÓ, 1996).

Segundo Nucci (2001), a falta de definição clara do termo "áreas verdes" e seus correlatos podem levar a falsas interpretações e a um uso político não muito correto, por planejadores mal intencionados. Acrescenta, ainda, que, na realidade, as metodologias utilizadas para medir estes índices ainda requerem estudos mais aprofundados e a definição de critérios mais claros. Portanto, não existem no Brasil recomendações para o sistema de áreas verdes no tocando mínimo de $\mathrm{m}^{2} /$ habitante, tamanho mínimo, raio de influência, posição, faixa etária, o tipo de uso, entre outros, como em alguns países.

Fernandes (2002) ressalta que a urbanização do Brasil resultou em cidades fragmentadas, onde, premidas por forças de mercado e por uma ação elitista e excludente do estado, a maioria dos pobres tem sido segregada e obrigada a viver em favelas, cortiços, loteamentos irregulares e clandestinos em condições habitacionais precárias, podendo, ainda, ser submetida a assentamentos informais e inadequados do ponto de vista das condições ambientais, em áreas centrais ou periféricas da cidade. A esse respeito, Kanashiro (2003) observa que a cidade passou a ser entendida como um emaranhado de problemas de ordem técnica e funcional, esquecendo-se dos valores pessoais, históricos e culturais, além das dimensões sensorial e psicológica das comunidades, as quais passaram a ser tratadas, inclusive, com a designação de "usuários" ou de "moradores".

E como Santos (1997) cita, as cidades são criadas para a economia e não para os cidadãos. A afirmação de Santos é evidente nas limitações entre a rua e casa, a redução do espaço público, o anonimato entre as pessoas, tornando a cidade cada vez mais funcional, o que contribui diretamente para o individualismo. As cidades transformam-se, transvestem-se em paraísos tecnológicos oferecendo aos suas habitantes falsas benesses. As coisas mais simples, como crianças brincando nas ruas ou os lugares de festas e de encontro desaparecem; as praças, transmutadas em concreto, revalecem; tudo isso somado faz com que as pessoas percam suas próprias referências (CARLOS, 1992).

\section{DISCUSSÃO}

O cenário atual de parques no Brasil é de extrema carência, e o mercado imobiliário tem permitido a iniciativa privada construir empreedimentos em diversas áreas onde se viabilizaria um parque para a melhoria da qualidade de vida. Sabe-se que sobre o aspecto urbano das cidades, principalmente quando se trata de lazer, entretenimento, esportes e espaço para shows e eventos, zonas de expansão urbana a critério de viabilidade orçamentária, opta-se por terrenos de baixo custo, de topografia plana e de localização tangente aos centros urbanos. Em certo ponto sabemos que é de interesse para o crescimento econômico para a cidade quando se trata de empregos, expansão da rede de concessão de infraestrutura e saneamento, e também de maior moradia para população. Mas sabe-se também que o incentivo para a existência de áreas verdes nesses locais são de caráter secundário e que o sistemas de planejamento para humanização e urbanização de uso comum dessas áreas é de fato antigo.

\section{CONCLUSÕES}

Este artigo pretende contribuir para o maior conhecimento do tema, suas funções urbanas e seus benefícios. No início do século XIX com a vinda da mão de obra para as cidades, a necessidade social e ambiental do cidadão se tornou essencial por conta da rotina de trabalho e da adaptabilidade de um ambiente urbano. Em cima desta migração, o conceito de Cidade-Jardim, exemplifica a floresta urbana como solução de uma vida rural-urbana, onde um depende do outro.

No passar dos anos com a defasagem do mercado imobiliário, por conta do capitalismo e grandes lucros, as empresas privadas viabilizam as construções com objetivos lucrativos tornando o conjunto urbano de crescimento desordenado e minimizando a função social dos parques urbanos, criando um emaranhado de problemas, esquecendo-se dos valores humanos, históricos, culturais alem da dimensão sensorial e psicológica da comunidade.

As cidades estão sendo criadas predominantemente para a economia e não para as pessoas, o anonimato das pessoas contribui diretamente para o individualismo, as crianças brincando na rua e os encontros desaparecem, as praças revalecem e tudo isso somado faz com que as pessoas percam suas próprias referências. 
De acordo com as pesquisas realizadas, conclui-se que o resultado é de oferta insuficiente. A falta de definição clara do termo "áreas verdes" pode levar a falsas interpretações e a um uso político não muito correto, por planejadores mal intencionados. Venho a acrescentar, ainda, que, na realidade, as metodologias utilizadas para medir estes índices ainda requerem reajustes, estudos mais aprofundados e a definição de critérios mais claros.

\section{REFERÊNCIAS}

ANDRADE, Inês El-Jaick. Jardins Históricos Cariocas: significação cultural e preservação. Rio de Janeiro: UFRJ/FAU, 2004. 1V, xvii, 181f. Dissertação de Mestrado em Arquitetura.

BENEVOLO, L. História da cidade. 2.ed. São Paulo: Perspectiva, 1993.

CARLOS, A. F. A. A cidade. São Paulo: Contexto, 1992.

CAVALHEIRO, F.; DEL PICCHIA, P.C.D. Áreas verdes: conceitos, objetivos e diretrizes para o planejamento. In: Anais... $1^{\circ}$ Congresso Brasileiro sobre Arborização Urbana e $4^{\circ}$ Encontro Nacional sobre Arborização Urbana. Vitória, ES, 1992. p. 29-38.

COSTA. L.M.S.A. Arborização Urbana e Parques Públicos. In: Anaisdo $1^{\circ}$ Seminário de Arborização Urbana. Rio de Janeiro. EBA/UFRJ. 1996.P.45-62. 196p.

FERrEIRA, A.D. O caso do Passeio Público da Cidade do Rio de Janeiro, Dissertação (Mestrado em Ciência Ambiental) - UFF, Niterói, 2005.

FERNANDES, Edésio e Rugani, Jurema M. (org). Cidade, memória e legislação - A preservação do patrimônio na perspectiva do direito urbanístico. Belo Horizonte: IAB-MG, 2002.

GEISER R.R. et. al. - Áreas verdes nas grandes cidades. In: XXVI CONGRESSO NACIONAL DE BOTÂNICA, Rio de janeiro, 1975.

GONÇALVES, Wantuelfer; PAIVA, Haroldo.Nogueira. Florestas Urbanas: planejamento para a melhoria da qualidade de vida. Viçosa. Minas Gerais. Aprenda Fácil, 2002. 180p.

HERCULANO, S.C.; PORTO, M.F.de.; FREITAS, C.M.de.; (organizadores). Qualidade de vida e Riscos Ambientais. Niterói, RJ: EdUFF, 2000. P.219-245. 334p.

HOWARD, Ebenezer. Cidades-Jardins de Amanhã. Tradução: Marco Aurélio Lagonego. Introdução: Dácio Araújo Benedito Ottoni. São Paulo: Estudos Urbanos, Série Arte e Vida Urbana, Hucitec, 1996.

KANASHIRO, M. A cidade e os sentidos: sentir a cidade. Revista Desenvolvimento e Meio Ambiente, $\mathrm{n}^{\circ} 7$, p. 155-160, jan./jun. 2003. Paraná. Editora UFPR.

LE CORBUSIER - Carta de Atenas, Hucitec-Edusp, 1989.

LLARDENT, L. R. A. Zonas verdes y espaços livres en la ciudad. Madrid: Closas Orcoyen, 1982.

LYNCH, K. A imagem da cidade: tradução Jefferson Luiz Camargo. São Paulo: Martins Fontes, 1997.

MACEDO, S.S. Quadro do Paisagismo no Brasil. (Coleção QUAPÁ, v.1) São Paulo. 1999.

MASCARÓ, L.R. de. Ambiência Urbana: urban enviroment. Porto Alegre, Rio Grande do Sul: Sagra: DC Luzzatto, 1996. 
MAZZEI, K.; COLSESANTI, M.T.M.; SANTOS, D.G. Áreas verdes urbanas, espaços livres para o lazer. Sociedade \& Natureza, Uberlândia, MG, v.19,n.1, p 33-43, jun. 2007.

NUCCI, J.C. (2001). Qualidade Ambiental e adensamento urbano: um estudo de ecologia e planejamento da paisagem aplicado ao distrito de Santa Cecília (MSP).-São Paulo: Humanitas/FFLCH/USP.2001.

REIS FILHO, N. G. Contribuição ao estudo da evolução urbana no Brasil (1500/

1720). São Paulo: EDUSP, 1968.

REZENDE, V.L.F.M. (2001). Dinâmicas Territoriais: Tendências e Desafios da Integração do Brasil Contemporâneo (Anais do Workshop Internacional de Dinâmicas Territoriais Brasília - DF - Brasil).

ROSENBERGER, R. S., and R. G. WALSH. "Nonmarket Valuation of Western Valley Ranchland Using Contingent Valuation." Journal of Agricultural and Resource Economics, 22(2), 1997, 296-309.

SANTOS, M. Espaço do cidadão. 3.ed. São Paulo: Nobel, 1997.

SEGAWA, H. Ao Amor do Público, Jardins do Brasil. Ed. São Paulo. SP. Studio Nobel / FAPESP. 1996. $255 \mathrm{p}$.

SILVA, J. A. Direito Ambiental Constitucional. São Paulo: Malheiros Editores, 1974. 243 p.

SOUZA, M.L. ABC do desenvolvimento urbano-Rio de janeiro: Bertrand Brasil. (2003) 192p.

TYRVAINEN L. ,VAANANEN H.. The economic value of urban forest amenities: an application of the contingent valuation methods. Landsc. Urban Plan., 43 (1998), pp. 105-118

VIEIRA, P.B.H. Uma visão geográfica das áreas verdes de Florianópolis, SC: estudo de caso do Parque Ecológico do Córrego Grande (PECG). Universidade Federal de Santa Catarina. Trabalho de Conclusão de Curso, Florianópolis, SC, 2004. 